\title{
Sleep Disorders and Menopause
}

\author{
Jinju Lee, Youngsin Han, Hyun Hee Cho, Mee-Ran Kim \\ Department of Obstetrics and Gynecology, College of Medicine, The Catholic University of Korea, Seoul, Korea
}

Sleep disorders are one of the main symptoms of menopause. Symptoms of sleep disorders that menopausal women complain about include falling asleep, frequent awakening and/or early morning awakening. There are many possible causes of sleep disorders in postmenopausal women, including vasomotor symptoms, ovarian hormone changes, restless legs syndrome, periodic leg movement syndrome, and obstructive sleep apnea. In this review, we discuss the relationship between menopause and sleep disorders.

Key Words: Menopause, Postmenopause, Sleep wake disorders

\section{INTRODUCTION}

Sleep is composed of rapid eye movement (REM) sleep, characterized by rapid eye movement and decreased muscle tone during sleep, and non-REM (NREM) sleep. Normally, sleep level repeats at a cycle of about 90 to 120 minutes between REM and NREM sleep and occurs about 5 cycles per night. REM sleep accounts for $20 \%$ to $25 \%$ of total sleep and NREM sleep $75 \%$ to $80 \%$ [1]. Sleep is controlled by two ways: the homeostatic process, and circadian process. The longer people stay awake, the more they sleep. The desire for sleep is one of the automatically-controlled homeostatic processes and depends on the amount of prior wakefulness. The circadian process is regulated by an endogenous circadian pacemaker. The suprachiasmatic nucleus mainly controls the circadian rhythm and is controlled by hypothalamus. Complex interactions among neurotransmitters, and interconnected neurons promote or suppress sleep and wakefulness [1]. Insomnia and fatigue are the most common symptoms of postmenopausal women. The definition of menopause refers to the period after 1 year has elapsed since the last menstrual period [2]. However, changes in hormones begins to occur 7 to 10 years before menopause, leading to a decrease in estradiol and inhibin and an increase in follicle-stimulating hormone and luteinizing hormone $[3,4]$. Women undergo physical and psychological changes as a result of hormonal changes, e.g., mood swing, anxiety, stress, forgetfulness, and sexual dysfunction $[5,6]$. Many women especially complain of sleep disorders at this time.

According to the Study of Women's Health Across the Nation (SWAN), the prevalence of sleep disorders increases with age. The prevalence of sleep disorders is variable, ranging from $16 \%$ to $42 \%$ in premenopausal women, from $39 \%$ to $47 \%$ in perimenopausal women, and from $35 \%$ to $60 \%$ in postmenopausal women [7]. Symptoms of sleep disorders that menopausal women complain about include falling asleep, frequent awakening and/or early morning awakening [8]. The etiology of sleep disorders in menopausal women isn't yet clear and seems to be different to according to the specific symptoms of sleep disorder. However potential factors include the menopause itself, aging, vasomotor symptoms, depression, anxiety, and many other medical condition, such as cardiovascular, endocrine disease, medication, and psychosocial factors [9].

Received: January 31, 2019 Revised: March 22, 2019 Accepted: April 17, 2019

Address for Correspondence: Mee-Ran Kim, Department of Obstetrics and Gynecology, College of Medicine, The Catholic University, 222 Banpo-daero, Seocho-gu, Seoul 06591, Korea

Tel: 82-2-2258-6170, E-mail: mrkim@catholic.ac.kr, ORCID: https://orcid.org/0000-0003-4492-0768 


\section{EFFECT OF MENOPAUSE ON SLEEP DISORDER AND TREATMENT}

\section{Vasomotor symptoms}

Vasomotor symptoms are the most common menopausal symptoms reported by $75 \%$ to $85 \%$ of postmenopausal women. Hot flashes are defined as a sudden sense of body heat or redness around the face and neck, often accompanying sweating and tachycardia. Most symptoms last for 1 to 2 years after menopause but rarely last for more than 10 years. Although many perimenopausal and postmenopausal women experience vasomotor symptoms, the cause is not clear. However, there is evidence that vasomotor symptoms are caused by estrogen withdrawal [10]. Some herbal treatments for menopausal symptoms contain hops $(\mathrm{Hu}-$ mulus lupulus L.) and its components which have high estrogenic potency. Although the mechanisms which hops relieves menopausal symtoms are not clearly understood, preparations based on hops have been found to decrease the severity and frequency of hot flashes [11].

In some studies, vasomotor symptoms of perimenopausal and postmenopausal women have been reported as one of the causes of sleep disturbances. A recent study has shown that vasomotor symptoms were related to poor sleep quality [12]. Other studies have supported this finding by suggesting that hormone therapy improves sleep quality [13]. However, some argue that there is no close relationship between vasomotor symptoms and sleep disorders. Young et al. [14] showed that menopause was not a strong predictor of sleep disorders, although perimenopausal and postmenopausal women have lower quality sleep than premenopausal women.

\section{Hormone change (estrogen/progesterone)}

Ovarian hormones have been reported to affect sleep disorders. Progesterone has both sedative and anxiolytic features. It stimulates the production of the NREM associated gamma-aminobutyric acid receptors by stimulating benzodiazepine receptors [15]. In addition, progesterone also acts as a respiratory stimulant and has been used to treat mild obstructive sleep apnea (OSA) [16]. The effect of estrogen on sleep structure is complex as estrogen has a wide range of effects that potentially affects sleep structure. First, it is associated with metabolism of norepinephrine, serotonin, and acetylcholine-neurotransmitters that affect sleep pattern. Estrogen has been proved to decrease sleep latency, the number of awakening after sleep occurs, and cyclic spontaneous arousals; and increase total sleep time $[17,18]$. Second, estrogen has a regulating effect on body temperature. During the night, estrogen plays a role in keeping the central body temperature low $[19,20]$. In mammals, estrogen is a hormone that regulates the temperature of the lowest body temperature during the night. When decreased estrogen, this time shift forward and the depth of the temperature drop changes [19]. Estrogen has a direct effect on mood by affecting the norepinephrine activity and serotonin response and uptake in the brain. All of these effects mean that estrogen would have an antidepressant effect $[20,21]$.

If we treat menopausal symptoms earlier in the menopause period with estrogen or estrogen-progesterone therapy, it will have a more beneficial effect in improving menopausal symptoms. Estrogen therapy is very effective in treating vasomotor symptoms, which improves sleep quality, and hormone replacement therapy is one of the main therapies for osteoporosis, mood disorder, and depression [22,23]. Studies have shown that estrogen replacement therapy improves sleep quality, enables falling asleep, decreases nighttime wakefulness and also reduces vasomotor symptoms [13]. Therefore, hormone replacement therapy is recommended for menopausal insomnia to improve the quality of sleep and life. For those who are starting hormone replacement therapy, use of low does estradiol rather than conjugated estrogen is more suitable.

\section{Melatonin}

Melatonin plays a major role in circadian rhythm, especially in sleep onset and in sleep maintenance through block arousal mechanism. These effects help to keep humans sleeping at night. However, the relationship between melatonin and menopause is still unclear. Melatonin levels decline with aging process but are not always associated with menopause. Melatonin levels decrease with aging before menopause, but then increase again over the years. In some studies, melatonin levels in postmenopausal women with insomnia were lower than those in premenopausal women [24]. Recently, more potent melatonin analogs (selective melatonin-1 [MT-1] and melatonin-2 [MT-2] receptor agonists) have been developed with extended effects and slow release melatonin preparations $[25,26]$. The MT-1 and MT-2 melatonin receptor ramelteon [27,28] 
was found to be effective in reducing total sleep time and sleep efficiency as well as reducing sleep initiation delay in patients with insomnia [29]. It has been shown that melatonergic antidepressant agomelatine, with strong MT-1 and MT-2 melatonergic agonists and relatively weak serotonin 5-hydroxytryptamine (2C) receptor antagonists $[30,31]$, is effective in treating insomnia with insomnia. In short, melatonin compounds can be useful in the treatment of insomnia [32-40].

\section{Mood disorders}

Mood disorders such as anxiety or depression are associated with sleep disorders in postmenopausal women [41]. Difficulty in falling asleep cause to anxiety, irritability, and inadequate sleep and possibly depression [42]. One of the main causes of depression is insomnia. In addition, women with hot flushes are more likely to develop depression. Women with depression and hot flushes have a lower quality of sleep than women without depression. Consequently, depression and hot flushes may have additional effects on sleep pattern.

\section{ASSOCIATED SLEEP DISORDER}

\section{Obstructive sleep apnea}

The incidence of OSA is significantly increased in postmenopausal women. In some studies, from $47 \%$ to $67 \%$ of postmenopausal women are reported to suffer from OSA $[43,44]$. Women tend to gain weight after menopause. Gained weight leads to the increased neck circumference, the body mass index, and waist-hip ratio [43-46]. Thus, the upper airway changes anatomically after menopause and causes problems like OSA during sleep $[15,47,48]$. Therefore, it seems that the prevalence of OSA in postmenopausal women is higher than in premenopausal women [46]. However, body weight is not the only factor that causes this disease. Some studies have reported that testosterone is a factor that aggravates OSA [49]. The primary treatment for OSA is positive airway pressure. The effect of hormone therapy, such as estrogen and progesterone, is controversial. While some studies show improvement in symptoms [50,51], others do not [52].

\section{Restless leg syndrome and periodic leg movement syndrome}

The restless leg syndrome (RLS) is a disorder which that causes an urge to move the leg accompanied by an uncomfortable sensation. Although RLS is not associ- ated with menopause and hormone therapy, it seems to increase with age [53]. The etiology is unclear but is known to be related to iron deficiency anemia, pregnancy, and uremia $[46,54]$. Periodic limb movement disorder (PLMD) is repetitive cramping or jerking of the legs during sleep occurring about every 20 to 40 seconds. PLMD is considered to cause to disrupt sleep and make arousal. The only reliable treatment for both diseases is dopamine agonist and also do not clearly respond to hormone therapy [55].

\section{CONCLUSION}

We have reviewed sleep disorders in postmenopausal women. We presented several factors and changes that affect women during the menopause transition and suggested the effect of these factors on sleep. However, because the etiology of sleep disorder in menopause is multifactorial, sleep disorders are simply a part of the aging. Although the cause of menopausal sleep disorder is not clear, some studies have reported that hormone therapy improves sleep quality and is considered a primary treatment if other causes are excluded. Despite of the effectiveness of hormone therapy, sleep disorders may simply be associated with limb movement syndrome, depression, anxiety and so on. Therefore, to manage effective sleep disorders in menopausal women, it is helpful to evaluate the cause. Further investigation by randomized controlled trials is needed to assess the efficacy of these treatments in postmenopausal women.

\section{ACKNOWLEDGMENTS}

The authors are grateful to Hongkwon Lee for their proofreading on the manuscript.

\section{CONFLICT OF INTEREST}

No potential conflict of interest relevant to this article was reported.

\section{REFERENCES}

1. Miller EH. Women and insomnia. Clin Cornerstone 2004; 6 Suppl 1B: S8-18.

2. Freedman RR. Postmenopausal physiological changes. Curr Top Behav Neurosci 2014; 21: 245-56.

3. Twiss JJ, Wegner J, Hunter M, Kelsay M, Rathe-Hart M, Salado W. 
Perimenopausal symptoms, quality of life, and health behaviors in users and nonusers of hormone therapy. J Am Acad Nurse Pract 2007; 19: 602-13.

4. Weber MT, Rubin LH, Maki PM. Cognition in perimenopause: the effect of transition stage. Menopause 2013; 20: 511-7.

5. Schmidt PJ. Mood, depression, and reproductive hormones in the menopausal transition. Am J Med 2005; 118 Suppl 12B: 54-8.

6. Sang JH, Kim TH, Kim SA. Flibanserin for treating hypoactive sexual desire disorder. J Menopausal Med 2016; 22: 9-13.

7. Kravitz HM, Joffe H. Sleep during the perimenopause: a SWAN story. Obstet Gynecol Clin North Am 2011; 38: 567-86.

8. Chokroverty S. Overview of sleep \& sleep disorders. Indian J Med Res 2010; 131: 126-40.

9. Guidozzi F. Sleep and sleep disorders in menopausal women. Climacteric 2013; 16: 214-9.

10. Al-Safi ZA, Santoro N. Menopausal hormone therapy and menopausal symptoms. Fertil Steril 2014; 101: 905-15.

11. Abdi F, Mobedi H, Roozbeh N. Hops for menopausal vasomotor symptoms: mechanisms of action. J Menopausal Med 2016; 22: $62-4$.

12. Lampio L, Polo-Kantola P, Polo O, Kauko T, Aittokallio J, Saaresranta T. Sleep in midlife women: effects of menopause, vasomotor symptoms, and depressive symptoms. Menopause 2014; 21: 121724.

13. Polo-Kantola P, Erkkola R, Irjala K, Pullinen S, Virtanen I, Polo O. Effect of short-term transdermal estrogen replacement therapy on sleep: a randomized, double-blind crossover trial in postmenopausal women. Fertil Steril 1999; 71: 873-80.

14. Young T, Rabago D, Zgierska A, Austin D, Laurel F. Objective and subjective sleep quality in premenopausal, perimenopausal, and postmenopausal women in the Wisconsin Sleep Cohort Study. Sleep 2003; 26: 667-72.

15. Manber R, Armitage R. Sex, steroids, and sleep: a review. Sleep 1999; 22: 540-55.

16. Empson JA, Purdie DW. Effects of sex steroids on sleep. Ann Med 1999; 31: 141-5.

17. Polo-Kantola P. Dealing with menopausal sleep disturbances. Sleep Med Clin 2008; 3: 121-31.

18. Scharf MB, McDannold MD, Stover R, Zaretsky N, Berkowitz DV. Effects of estrogen replacement therapy on rates of cyclic alternating patterns and hot-flush events during sleep in postmenopausal women: a pilot study. Clin Ther 1997; 19: 304-11.

19. Freedman RR, Woodward S. Core body temperature during menopausal hot flushes. Fertil Steril 1996; 65: 1141-4.

20. Eichling PS, Sahni J. Menopause related sleep disorders. J Clin Sleep Med 2005; 1: 291-300.

21. Grigoriadis S, Kennedy SH. Role of estrogen in the treatment of depression. Am J Ther 2002; 9: 503-9.

22. Welton AJ, Vickers MR, Kim J, Ford D, Lawton BA, MacLennan
$\mathrm{AH}$, et al. Health related quality of life after combined hormone replacement therapy: randomised controlled trial. BMJ 2008; 337: a1190.

23. Barnabei VM, Grady D, Stovall DW, Cauley JA, Lin F, Stuenkel $\mathrm{CA}$, et al. Menopausal symptoms in older women and the effects of treatment with hormone therapy. Obstet Gynecol 2002; 100: 1209-18.

24. Okatani Y, Morioka N, Wakatsuki A. Changes in nocturnal melatonin secretion in perimenopausal women: correlation with endogenous estrogen concentrations. J Pineal Res 2000; 28: 111-8.

25. Lemoine P, Zisapel N. Prolonged-release formulation of melatonin (Circadin) for the treatment of insomnia. Expert Opin Pharmacother 2012; 13: 895-905.

26. Lemoine P, Nir T, Laudon M, Zisapel N. Prolonged-release melatonin improves sleep quality and morning alertness in insomnia patients aged 55 years and older and has no withdrawal effects. J Sleep Res 2007; 16: 372-80.

27. Kato K, Hirai K, Nishiyama K, Uchikawa O, Fukatsu K, Ohkawa S, et al. Neurochemical properties of ramelteon (TAK-375), a selective MT1/MT2 receptor agonist. Neuropharmacology 2005; 48: 301-10.

28. Miyamoto M. Pharmacology of ramelteon, a selective MT1/MT2 receptor agonist: a novel therapeutic drug for sleep disorders. CNS Neurosci Ther 2009; 15: 32-51.

29. Pandi-Perumal SR, Srinivasan V, Spence DW, Moscovitch A, Hardeland R, Brown GM, et al. Ramelteon: a review of its therapeutic potential in sleep disorders. Adv Ther 2009; 26: 613-26.

30. Hardeland R, Poeggeler B, Srinivasan V, Trakht I, Pandi-Perumal SR, Cardinali DP. Melatonergic drugs in clinical practice. Arzneimittelforschung 2008; 58: 1-10.

31. Millan MJ, Gobert A, Lejeune F, Dekeyne A, Newman-Tancredi A, Pasteau V, et al. The novel melatonin agonist agomelatine (S20098) is an antagonist at 5-hydroxytryptamine $2 \mathrm{C}$ receptors, blockade of which enhances the activity of frontocortical dopaminergic and adrenergic pathways. J Pharmacol Exp Ther 2003; 306: 954-64.

32. Dorsey CM, Lee KA, Scharf MB. Effect of zolpidem on sleep in women with perimenopausal and postmenopausal insomnia: a 4-week, randomized, multicenter, double-blind, placebo-controlled study. Clin Ther 2004; 26: 1578-86.

33. Ohayon MM, O'Hara R, Vitiello MV. Epidemiology of restless legs syndrome: a synthesis of the literature. Sleep Med Rev 2012; 16 : 283-95.

34. Soares CN, Joffe H, Rubens R, Caron J, Roth T, Cohen L. Eszopiclone in patients with insomnia during perimenopause and early postmenopause: a randomized controlled trial. Obstet Gynecol 2006; 108: 1402-10.

35. Srinivasan V, Brzezinski A, Pandi-Perumal SR, Spence DW, Cardinali DP, Brown GM. Melatonin agonists in primary insomnia and depression-associated insomnia: are they superior to sedative- 
hypnotics? Prog Neuropsychopharmacol Biol Psychiatry 2011; 35 : 913-23.

36. Zlotos DP, Jockers R, Cecon E, Rivara S, Witt-Enderby PA. MT1 and MT2 melatonin receptors: ligands, models, oligomers, and therapeutic potential. J Med Chem 2014; 57: 3161-85.

37. Kennedy SH, Emsley R. Placebo-controlled trial of agomelatine in the treatment of major depressive disorder. Eur Neuropsychopharmacol 2006; 16: 93-100.

38. Innes KE, Selfe TK, Agarwal P. Prevalence of restless legs syndrome in North American and Western European populations: a systematic review. Sleep Med 2011; 12: 623-34.

39. Srinivasan V, De Berardis D, Shillcutt SD, Brzezinski A. Role of melatonin in mood disorders and the antidepressant effects of agomelatine. Expert Opin Investig Drugs 2012; 21: 1503-22.

40. Manconi M, Ulfberg J, Berger K, Ghorayeb I, Wesström J, Fulda S, et al. When gender matters: restless legs syndrome. Report of the "RLS and woman" workshop endorsed by the European RLS Study Group. Sleep Med Rev 2012; 16: 297-307.

41. Parry BL, Fernando Martínez L, Maurer EL, López AM, Sorenson D, Meliska CJ. Sleep, rhythms and women's mood. Part II. Menopause. Sleep Med Rev 2006; 10: 197-208.

42. Terauchi M, Hiramitsu S, Akiyoshi M, Owa Y, Kato K, Obayashi $\mathrm{S}$, et al. Associations between anxiety, depression and insomnia in peri- and post-menopausal women. Maturitas 2012; 72: 61-5.

43. Dancey DR, Hanly PJ, Soong C, Lee B, Hoffstein V. Impact of menopause on the prevalence and severity of sleep apnea. Chest 2001; 120: 151-5.

44. Resta O, Bonfitto P, Sabato R, De Pergola G, Barbaro MP. Prevalence of obstructive sleep apnoea in a sample of obese women: effect of menopause. Diabetes Nutr Metab 2004; 17: 296-303.

45. Donato GB, Fuchs SC, Oppermann K, Bastos C, Spritzer PM. Association between menopause status and central adiposity measured at different cutoffs of waist circumference and waist-to-hip ratio. Menopause 2006; 13: 280-5.
46. Resta O, Caratozzolo G, Pannacciulli N, Stefàno A, Giliberti T, Carpagnano GE, et al. Gender, age and menopause effects on the prevalence and the characteristics of obstructive sleep apnea in obesity. Eur J Clin Invest 2003; 33: 1084-9.

47. Vorona RD, Winn MP, Babineau TW, Eng BP, Feldman HR, Ware JC. Overweight and obese patients in a primary care population report less sleep than patients with a normal body mass index. Arch Intern Med 2005; 165: 25-30.

48. Bass J, Turek FW. Sleepless in America: a pathway to obesity and the metabolic syndrome? Arch Intern Med 2005; 165: 15-6.

49. Phillips BA, Collop NA, Drake C, Consens F, Vgontzas AN, Weaver TE. Sleep disorders and medical conditions in women. Proceedings of the Women \& Sleep Workshop, National Sleep Foundation, Washington, DC, March 5-6, 2007. J Womens Health (Larchmt) 2008; 17: 1191-9.

50. Manber R, Kuo TF, Cataldo N, Colrain IM. The effects of hormone replacement therapy on sleep-disordered breathing in postmenopausal women: a pilot study. Sleep 2003; 26: 163-8.

51. Shahar E, Redline S, Young T, Boland LL, Baldwin CM, Nieto FJ, et al. Hormone replacement therapy and sleep-disordered breathing. Am J Respir Crit Care Med 2003; 167: 1186-92.

52. Nowakowski S, Meliska CJ, Martinez LF, Parry BL. Sleep and menopause. Curr Neurol Neurosci Rep 2009; 9: 165-72.

53. Phillips B. Movement disorders: a sleep specialist's perspective. Neurology 2004; 62: S9-16.

54. Viola-Saltzman M, Watson NF, Bogart A, Goldberg J, Buchwald D. High prevalence of restless legs syndrome among patients with fibromyalgia: a controlled cross-sectional study. J Clin Sleep Med 2010; 6: 423-7.

55. Littner MR, Kushida C, Anderson WM, Bailey D, Berry RB, Hirshkowitz M, et al. Practice parameters for the dopaminergic treatment of restless legs syndrome and periodic limb movement disorder. Sleep 2004; 27: 557-9. 